\title{
Hydrothermal Synthesis of a Novel Uranium Oxalate/Glycolate via In-situ Ligand Formation
}

Karah E. Knope ${ }^{\dagger}$ and Christopher L. Cahill ${ }^{*},+\neq$

Supplementary Information 

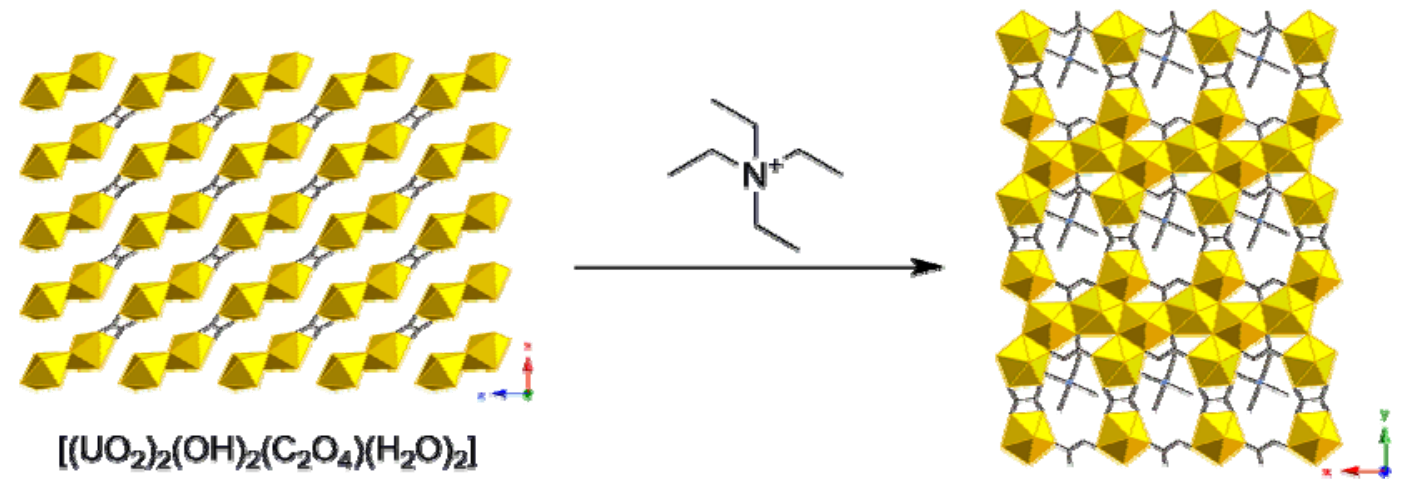

SI 1. Schematic showing the structural differences resulting from the addition of tetraethylammonium hydroxide. $\left[\left(\mathrm{UO}_{2}\right)_{2}(\mathrm{OH})_{2}\left(\mathrm{C}_{2} \mathrm{O}_{4}\right)\left(\mathrm{H}_{2} \mathrm{O}\right)_{2}\right]$ crystallizes in a triclinic space group $P-1(\mathrm{a}=6.097, \mathrm{~b}=5.547, \mathrm{c}=7.806, \alpha=89.353, \beta=94.387, \gamma=97.646$.

Synthesis of $\left[\left(\mathrm{UO}_{2}\right)_{2}(\mathrm{OH})_{2}\left(\mathrm{C}_{2} \mathrm{O}_{4}\right)\left(\mathrm{H}_{2} \mathrm{O}\right)_{2}\right]$

Uranium oxynitrate hexahydrate $(0.141 \quad \mathrm{~g}, \quad 0.28 \quad \mathrm{mmol}), \quad 1,4-$ diazabicyclo[2.2.2] octane $(0.033 \mathrm{~g}, 0.29 \mathrm{mmol})$, and distilled water $(5 \mathrm{~g}, 278 \mathrm{mmol})$ were placed into a 23mL Teflon-lined Parr bomb in the molar ratios of 1.0:1.0:992 respectively. The $\mathrm{pH}$ was adjusted to 1.4 using concentrated $\mathrm{HNO}_{3}$. The reaction vessel was then sealed and heated statically at $120{ }^{\circ} \mathrm{C}$ for 14 days. Upon cooling to room temperature, a clear yellow solution ( $\mathrm{pH} 2.1)$ was decanted and yellow plates were obtained. The crystals were washed with distilled water followed by ethanol and then allowed to air dry at room temperature. Yield: 51\% (based on uranium). A single crystal of the sample was isolated from the bulk for single crystal analysis and the cell matched that previously reported by Duvieubourg et al. ${ }^{1}$ Powder x-ray diffraction data were collected using a Rigaku Miniflex diffractometer $\left(\mathrm{Cu} \mathrm{K \alpha}, 3-60^{\circ}\right)$ and the observed pattern matched the calculated pattern. 


\section{Synthesis of DABCO hydrate.}

Synthesis. 1,4-diazabicyclo[2.2.2] octane $(0.160 \mathrm{~g}, 1.43 \mathrm{mmol})$ and distilled water $(5 \mathrm{~g}$, $278 \mathrm{mmol}$ ) were placed into a $23 \mathrm{~mL}$ Teflon-lined Parr bomb in the molar ratios of 5.0:992 respectively, $\mathrm{pH} 10.1$. The reaction vessel was then sealed and heated statically at $180{ }^{\circ} \mathrm{C}$ for 1 day. Upon cooling to room temperature, a clear brown solution was obtained. The solvent was allowed to evaporate at room temperature resulting in colorless crystals.

A single crystal of $\left(\mathrm{C}_{6} \mathrm{H}_{12} \mathrm{~N}_{2}\right) \cdot \mathrm{H}_{2} \mathrm{O}$ was selected from the bulk and mounted on a glass fiber. Reflections were collected at $120 \mathrm{~K}$ using a Bruker SMART diffractometer equipped with an APEX II CCD detector using Mo $\mathrm{K} \alpha$ radiation $(\lambda=0.7103 \AA)$ and one omega scan covering $125^{\circ}$ was collected. This was not intended to be a full data set and instead simply allowed structure solution, rudimentary refinement and phase identification. The data were integrated with the SAINT software package and corrected for absorption using SADABS. The structure was solved in a hexagonal space group P32 using SHELX-97 and was refined using SHELX-97 within the WinGX software suite. $\left(\mathrm{C}_{6} \mathrm{H}_{12} \mathrm{~N}_{2}\right) \cdot \mathrm{H}_{2} \mathrm{O}$ crystallizes in a hexagonal space group $P 32 .(\mathrm{a}=11.019, \mathrm{~b}=11.019, \mathrm{c}=$ $\left.15.2380, \gamma=120^{\circ}\right)$. 


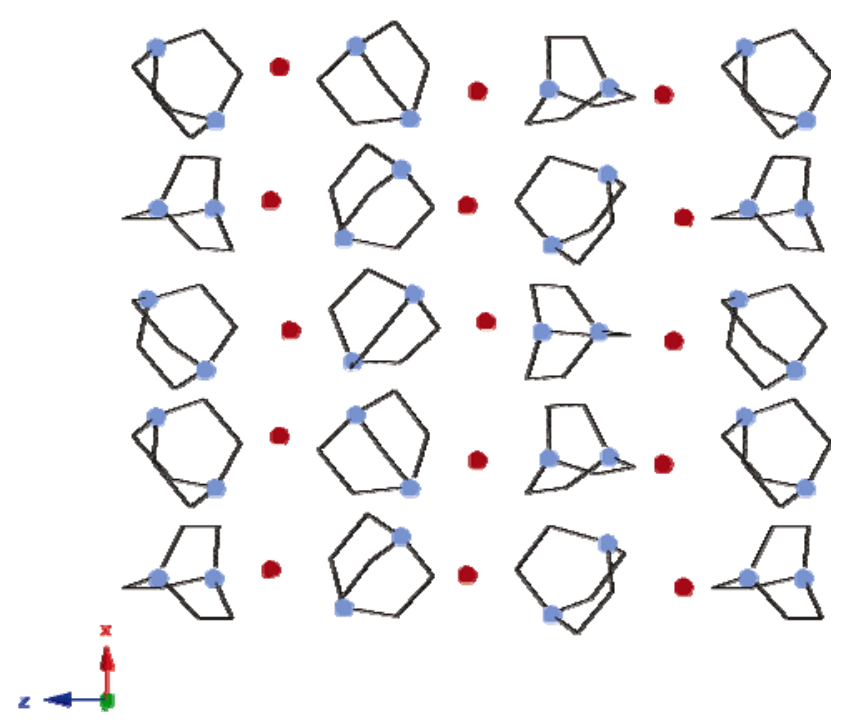

SI 2. Packing of $\left(\mathrm{C}_{6} \mathrm{H}_{12} \mathrm{~N}_{2}\right) \cdot \mathrm{H}_{2} \mathrm{O}$. Hydrogen atoms are omitted for clarity

\section{Synthesis of $\left(\mathrm{C}_{6} \mathrm{H}_{14} \mathrm{~N}_{2}\right)\left(\mathrm{NO}_{3}\right)_{2}$.}

Synthesis. 1,4-diazabicyclo[2.2.2]octane $(0.098 \mathrm{~g}, 0.87 \mathrm{mmol})$ and distilled water ( $5 \mathrm{~g}, 278 \mathrm{mmol}$ ) were placed into a $23 \mathrm{~mL}$ Teflon-lined Parr bomb in the molar ratios of 1.0:320 respectively. The $\mathrm{pH}$ was adjusted to 1.5 using concentrated $\mathrm{HNO}_{3}$. The reaction vessel was then sealed and heated statically at $120^{\circ} \mathrm{C}$ for 10 days. Upon cooling to room temperature, a clear colorless solution was obtained. The solvent was allowed to evaporate at room temperature resulting in colorless crystals.

Crystallographic Data: A single crystal of $\left(\mathrm{C}_{6} \mathrm{H}_{14} \mathrm{~N}_{2}\right)\left(\mathrm{NO}_{3}\right)_{2}$ was selected from the bulk and mounted on a glass fiber. Reflections were collected at room temperature using a Bruker SMART diffractometer equipped with an APEX II CCD detector using Mo K $\alpha$ radiation $(\lambda=0.7103 \AA)$ and both omega and phi scans. The data were integrated with the SAINT software package and corrected for absorption using SADABS. The structure was solved in a monoclinic space group P $21 / n$ with SHELX-97 and was refined using SHELX-97 within the WinGX software suite. Tests for missing symmetry using Platon 
indicated that $P 2_{1} / n$ was the correct space group. All atoms in the structure were found using Fourier difference maps and ultimately all non hydrogen atoms were refined anisotropically. Crystallizes in a monoclinic space group $P 2_{1} / n(a=11.4887(4), b=$ 6.8821(2) $\left.\AA, c=12.6838(5) \AA, \beta=91.2470(10)^{\circ}\right){ }^{2}$

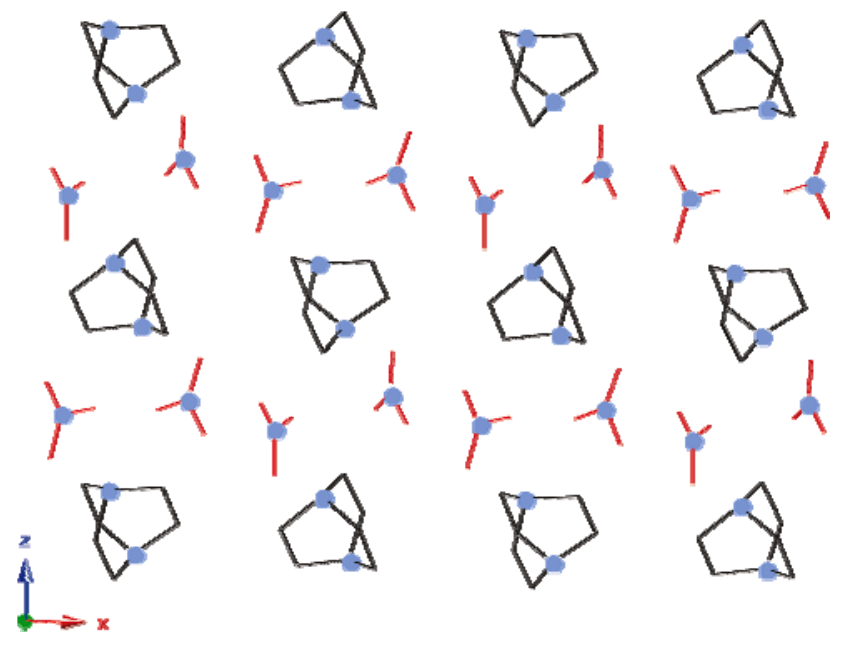

SI 3. Packing of $\left(\mathrm{C}_{6} \mathrm{H}_{14} \mathrm{~N}_{2}\right)\left(\mathrm{NO}_{3}\right)_{2}$. Hydrogen atoms are omitted for clarity. 


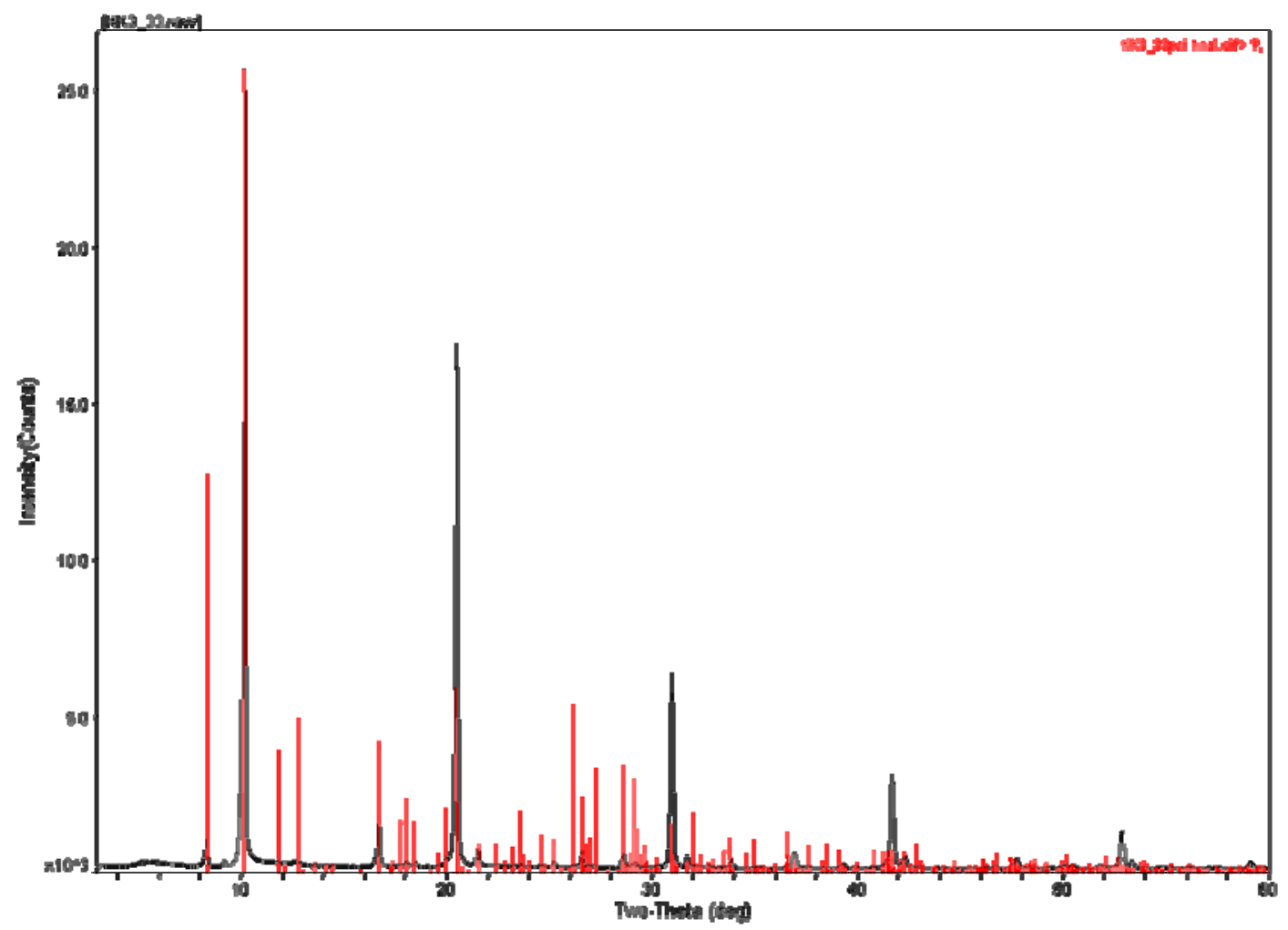

SI 4. Powder diffraction spectra of title compound with calculated pattern overlay confirming phase purity. 


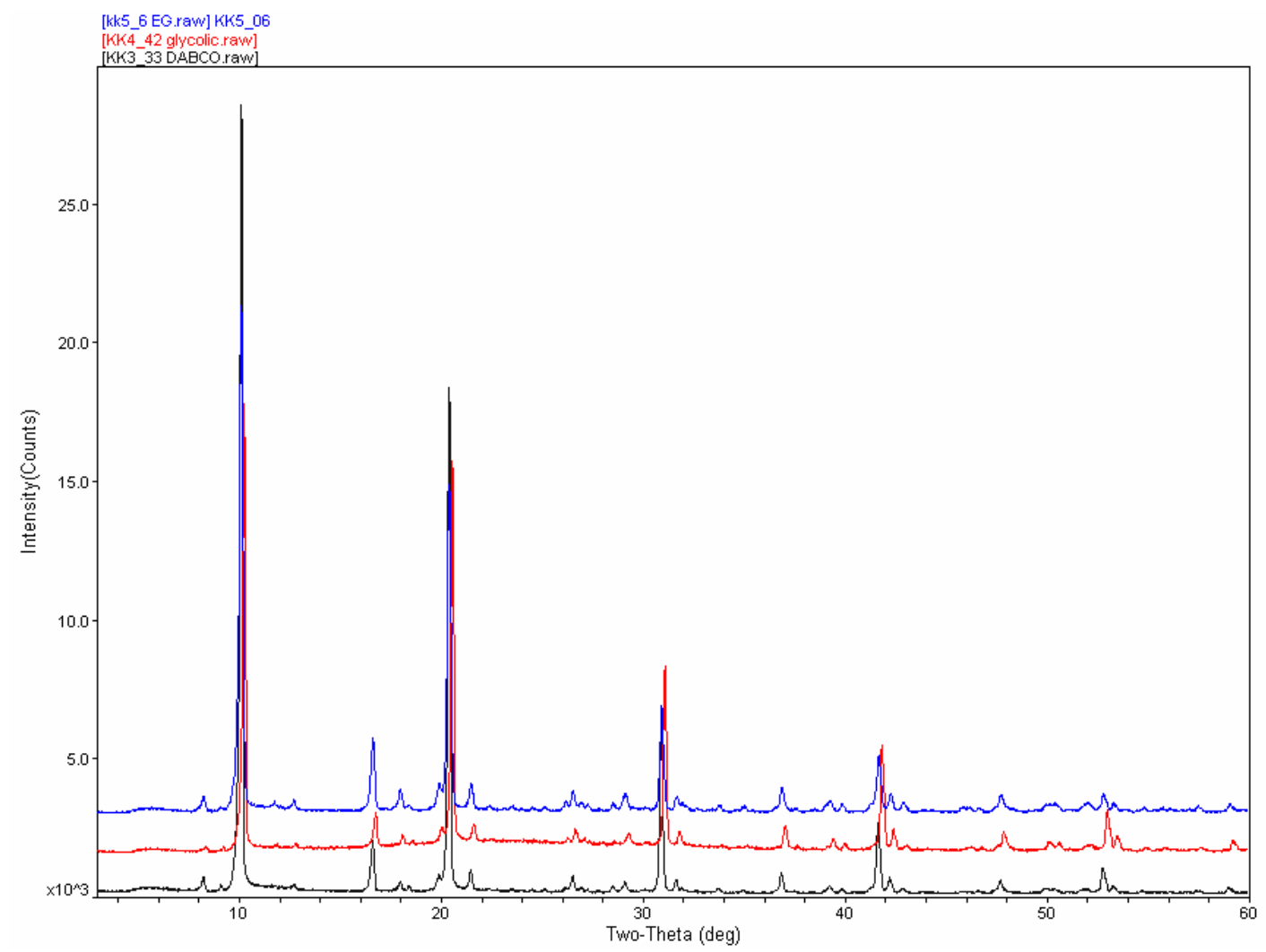

SI 5. Powder diffraction spectra overlay of title compound prepared from DABCO (black), glycolic acid (red), and ethylene glycol (blue).

\section{References}

(1) Duvieubourg, L.; Nowogrocki, G.; Abraham, F.; Grandjean, S. J. Solid State Chem. 2005, 178, 3437-3444.

(2) Knope, K. E.; Cahill, C. L. Acta Crystallogr., Sect. E. 2007, E63, 02955. 